\title{
Detection of ALK fusion transcripts in plasma of non-small cell lung cancer patients using a novel RT-PCR based assay
}

\begin{abstract}
Simon Heeke $\mathrm{1}^{1,2,3} \wedge^{*}$, Jonathan Benzaquen ${ }^{1,2,4}$, Audrey Vallee ${ }^{5}$, Maryline Allegra $^{3}$, Julien Mazieres ${ }^{6}$, Julien Fayada ${ }^{3}$, Jaya Rajamani ${ }^{7}$, Michael Lee ${ }^{7}$, Ellen Ordinario ${ }^{7}$, Angelica Tiotiu ${ }^{8}$, Jacques Cadranel$^{9}$, Michel Poudenx ${ }^{10}$, Denis Moro-Sibilot ${ }^{11}$, Fabrice Barlesi ${ }^{12,13}$, Radj Gervais ${ }^{14}$, Juliette Thariat ${ }^{15}$, Virginie Tanga $^{3}$, Jacques Boutros ${ }^{4}$, Marius Ilié ${ }^{1,2,3,16}$, Véronique Hofman ${ }^{1,2,3,16}$, Charles-Hugo Marquette ${ }^{1,2,4,16}$, Marc G. Denis ${ }^{17}$, Paul Hofman ${ }^{1,2,16}$; on behalf of the STALKLUNG01 Study Consortium Investigators ${ }^{* *}$

${ }^{1}$ University Côte d'Azur, Nice, France; ${ }^{2}$ Team 4 IRCAN, Inserm U1081/CNRS 7284, IRCAN, Nice, France; ${ }^{3}$ Laboratory of Clinical and Experimental Pathology, Biobank BB-0033-00025, Centre Hospitalier Universitaire Nice, Nice, France; ${ }^{4}$ Pulmonary Department, Pasteur Hospital, Nice, France; ${ }^{5}$ Department of Biochemistry and Molecular Biology, Nantes University Hospital, Nantes, France; ${ }^{6}$ Service de Pneumologie, Chu de Toulouse, Université Paul Sabatier, Toulouse, France; ${ }^{7}$ Roche Molecular Systems, Inc., Pleasanton, CA, USA; ${ }^{8}$ Pulmonology Dept, University Hospital, Nancy, France; ${ }^{9}$ Service de Pneumologie, AP-HP, Hôpital Tenon and Sorbonne Université, Paris, France; ${ }^{10}$ Department of Medical Oncology, Centre Antoine-Lacassagne, Nice, France; ${ }^{11}$ OncologieThoracique SHUPP, CHU Grenoble-Alpes, Grenoble, France; ${ }^{12}$ Gustave Roussy Cancer Campus, Villejuif, France; ${ }^{13}$ Aix Marseille University, CNRS, INSERM, CRCM, AP-HM, Marseille, France; ${ }^{14}$ CRLCC Francois Baclesse, Caen, France; ${ }^{15}$ Service de Radiothérapie, Centre François Baclesse/ARCHADE-Normandie Université, Caen, France; ${ }^{16} \mathrm{FHU}$ OncoAge, Centre Hospitalier Universitaire Nice, Nice, France; ${ }^{17}$ Medical Oncology Department, Cancer Institute, Nancy, France

Contributions: (I) Conception and design: S Heeke, MG Denis, P Hofman; (II) Administrative support: J Fayada; (III) Provision of study materials or patients: J Benzaquen, J Mazieres, J Rajamani, M Lee, E Ordinario, A Tiotiu, J Cadranel, M Poudenx, D Moro-Sibilot, F Barlesi, R Gervais, J Thariat, J Boutros, M Ilie, V Hofman, CH Marquette, MG Denis, P Hofman; (IV) Collection and assembly of data: S Heeke, J Benzaquen, A Vallee, M Allegra, J Fayada, V Tanga, M Ilie, MG Denis, P Hofman; (V) Data analysis and interpretation: S Heeke, A Valle, J Rajamani, M Lee, E Ordinario, MG Denis, P Hofman; (VI) Manuscript writing: All authors; (VII) Final approval of manuscript: All authors.
\end{abstract}

Correspondence to: Paul Hofman. University Côte d'Azur, Nice, France. Email: hofman.p@chu-nice.fr.

Background: Detection of genomic rearrangements, like anaplastic lymphoma kinase (ALK) fusions, is a pivotal requirement in non-small cell lung cancer (NSCLC) for the initiation of a targeted treatment. While tissue testing remains the gold standard, detection of these alterations using liquid biopsies is an unmet need. To enable the detection of $A L K$ rearrangements from circulating-free RNA (cfRNA) from NSCLC patients, we have evaluated a novel reverse transcription PCR (RT-PCR) based assay.

Methods: Sixty-six patients with advanced stage NSCLC were included in the study. ALK status was determined by immunohistochemistry (IHC) and/or FISH on tissue sections. For the detection of $A L K$ rearrangements from $2 \mathrm{ml}$ plasma collected in EDTA or Streck BCT DNA tubes, cfRNA was extracted using a prototype cfRNA sample preparation method and tested by a novel multiplex ALK/RET RT-PCR assay (Roche).

Results: Of the forty-two patients with an $A L K$ rearrangement, 30 (71\%) were included at baseline. In 10 of the baseline patients, an ALK rearrangement was detected by RT-PCR [baseline sensitivity 33.33\% (95\% CI: $17.29-52.81 \%)]$. All 24 negative ALK IHC/FISH-negative patients were negative using the RT-PCR based assay (specificity $=100 \%$ ).

Conclusions: The prototype Roche ALK/RET RT-PCR assay was able to detect ALK fusion transcripts in the plasma of NSCLC patients at baseline as well as at disease progression with limited sensitivity but high

\footnotetext{
$\wedge$ ORCID: 0000-0002-5916-534X.

*Present affiliation: Department of Thoracic H\&N Medical Oncology, MD Anderson Cancer Center, Houston, TX, USA.

**The STALKLUNG01 Investigators are listed in the supplement.
} 
specificity. Consequently, this assay could potentially be considered to select patients for an ALK-targeting therapy when tissue samples are lacking.

Keywords: Non-small cell lung cancer (NSCLC); anaplastic lymphoma kinase (ALK); reverse transcription PCR (RT-PCR); circulating free RNA (cfRNA); liquid biopsy

Submitted Dec 09, 2020. Accepted for publication Mar 14, 2021.

doi: $10.21037 / \mathrm{atm}-20-7900$

View this article at: http://dx.doi.org/10.21037/atm-20-7900

\section{Introduction}

Approximately $4 \%$ of advanced non-small cell lung cancer (NSCLC) patients harbor a genomic rearrangement of the anaplastic lymphoma kinase $(A L K)$ gene which can be targeted by tyrosine-kinase inhibitors (1). To enable this targeted treatment, the detection of the genomic rearrangement is pivotal. $A L K$ rearrangements are primarily detected by immunohistochemistry assays (IHC) or fluorescence in-situ hybridization (FISH) using tissue sections (2). Recently, NGS assays which allow the simultaneous detection of several genomic rearrangements using DNA or RNA isolated from tissue have also been developed (3). However, tissue sections are not always available or are limited in material. Consequently, the use of liquid biopsies could overcome this limitation, enabling the detection of $A L K$ rearrangements from patient plasma samples at baseline to stratify patients for the respective treatment.

Here we describe the evaluation of a novel real time, reverse transcription PCR-based (RT-PCR) assay for the detection of $A L K$ rearrangements from circulating free RNA (cfRNA) from limited amounts of plasma in a retrospective cohort of advanced NSCLC patients. We present the following article in accordance with the STARD reporting checklist (available at http://dx.doi.org/10.21037/ atm-20-7900).

\section{Methods}

\section{Patient samples}

Sixty-six patients with advanced stage lung adenocarcinoma were prospectively included as supplement to the prospective multicentric STALKLUNG trial assessing circulating tumor cells (CTCs) for the use of ALK testing in NSCLC patients (NCT02372448) (4). Formalinfixed, paraffin embedded tissue sections and plasma were collected from each patient. Up to $8 \mathrm{ml}$ of blood was drawn per patient using either K2EDTA (BD vacutainer, BD, Franklin Lakes, USA) or Cell-Free DNA BCT (Streck, La Vista, USA) collection tubes. All EDTA samples were processed within $2 \mathrm{~h}$ of phlebotomy and all Streck samples were processed within $72 \mathrm{~h}$. Plasma was obtained by double centrifugation at $2000 \times \mathrm{g}$ at $4{ }^{\circ} \mathrm{C}$ as described previously and plasma was stored at $-80{ }^{\circ} \mathrm{C}$ until extraction of cfRNA (5). All patients provided signed informed consent and the study was approved by the local ethics committee (No: 2014A00417-40) and complied with the declaration of Helsinki (as revised in 2013).

\section{ALK tissue analysis}

ALK status from tissue was obtained as part of the STALKLUNG trial (NCT02372448). Tissue sections were evaluated either using the Vysis break-apart FISH kit (Abbott Molecular Inc., Des Plaines, USA) or by IHC using the D5F3 assay (Roche Diagnostics, Basel, Switzerland) as described previously (6).

\section{cfRNA sample preparation and RT-PCR assay}

For the detection of $A L K$ rearrangements from plasma, the investigational cfRNA sample preparation method and ALK/RET RT-PCR assay were used following precisely the manufacturer's instructions. Briefly, $2 \mathrm{~mL}$ of previously frozen plasma were used for cfRNA isolation. Samples were incubated with $3 \mathrm{~mL}$ lysis buffer and $400 \mu \mathrm{L}$ Proteinase K for 30 minutes. Afterwards, the cfRNA was isolated using provided spin filter columns and a microcentrifuge. To avoid contamination with DNA, a DNAse digestion step for 15 minutes at room temperature was performed directly on the column. cfRNA was eluted in a final volume of $60 \mu \mathrm{L}$ elution buffer. All buffers and columns were part of the investigational plasma cfRNA kit. RNA concentration was 
Table $1 A L K$ and RET fusions detected by the Roche ALK/RET RT-PCR prototype assay

\begin{tabular}{lc}
\hline Target gene & Fusion partners \\
\hline ALK (7 fusion variants) & EML4 exon 13, EML4 exon 20, EML4 exon 6, EML4 exon 2, EML4 exon 18, KIF5B exon 17, KIF5B exon 24 \\
RET (6 fusion variants) & KIF5B exon 15, KIF5B exon 16, KIF5B exon 22, KIF5B exon 23, CCDC6 exon 1, NCOA4 exon 6 \\
\hline
\end{tabular}

$A L K$, anaplastic lymphoma kinase; RT-PCR, reverse transcription PCR.

measured using a NanoDrop 2000 Spectrophotometer (Thermo Fisher Scientific, Waltham, USA).

$A L K$ and RET fusion status was determined by a proprietary TaqMan-based RT-PCR multiplex assay on the user-defined channel of the cobas 4800 system (Roche, Pleasanton, USA). For amplification using RT-PCR, $25 \mu \mathrm{L}$ of cfRNA input was added to a RT-PCR reaction mix comprised of forward and reverse primers, labeled probes, buffer, cosolvents, dNTPs, UNG, and DNA polymerase to a final volume of $50 \mu \mathrm{L}$. Each cfRNA sample was tested in a single PCR reaction on a 96-well plate. The RT-PCR thermal cycling profile includes steps for UNG digestion, followed by cDNA synthesis and standard PCR cycling conditions for amplification and fluorescence detection (7).

The assay is designed to detect fusion partner genes flanking the fusion exon junction and covers the most common $A L K$ and RET rearrangements, including $95 \%$ of $A L K$ and $96 \%$ of RET fusions in the COSMIC database (COSMIC v86), in a single reaction using $25 \mu \mathrm{L}$ cfRNA input per sample. $A L K$ and RET rearrangements covered by the assay are highlighted in Table 1 . In addition to oligonucleotides covering the $A L K$ and RET fusions, the reagent mix includes oligonucleotides detecting the expression of a control gene to serve as an internal control for cfRNA input. Each PCR plate run includes a positive control containing $A L K$ and RET rearranged armored RNA particles as well as a water only notemplate negative control. The run is considered valid only if the positive control is amplified and the negative control is not amplified. For the detection of the fusions, a proprietary algorithm has been developed. A cfRNA sample is determined to be valid if the expression of the internal control gene is detected within a pre-specified Cycle Threshold (Ct) range. A fusion is defined to be present if the amplification of the respective fusion reaches a Ct value that is below a pre-specified cycle number. If all the pre-specified parameters are met, the sample is called fusion positive. Failure of the internal, positive, or negative controls leads to a non-interpretable result that requires repetition of the assay/sample.
For the data analysis, the underlying $A L K$ rearrangement status was blinded to the investigator and data analyst.

\section{Statistical analysis}

Assay specifications like sensitivity, specificity, negative predictive value (NPV) and positive predictive value (PPV) were calculated using Med Calc v18 (MedCalc Software Ltd, Ostend, Belgium). For all the other statistics, R software v3.6.3 (R foundation for statistical computing, Vienna, Austria) was used.

\section{Results}

In total, sixty-six patients were included in the study. Fortytwo patients (64\%) were $A L K$ rearrangement positive and twenty-four $(36 \%)$ patients were ALK negative as determined by FISH/IHC. All patients' characteristics are summarized in Table 2.

Additionally, patient populations, classified by disease progression and $A L K$ status based on RT-PCR testing, are presented in Figure 1. All PCR control and patient samples were valid, and runs were completed successfully. Interestingly, the internal control Ct values for the $A L K$ negative samples were lower than for the $A L K$ positive samples (mean $A L K$ positive $=26.1 v s$. mean $A L K$ negative $=27.9$; student's two sided $t$-test consistent with Figure 2, $\mathrm{P}=0.047$ ). Additionally, we saw a statistically significant inverse correlation between the $\mathrm{Ct}$ value of the internal control and the total amount of cfRNA (Pearson's $r=-0.32$; 95\% CI: -0.57 to $-0.02 ; \mathrm{P}=0.039$ ) (Figure $\mathrm{S} 1$ ).

Of the 42 ALK FISH/IHC positive patients, 30 (71\%) TKI-naïve baseline patients were included (Figures 1,3). ALK rearrangements were detected by RT-PCR in 10/30 patients at baseline highlighting a sensitivity of $33.33 \%$ (95\% CI: $17.29-52.81 \%$ ). Of the 24 ALK FISH/IHC negative patients, all 24 patients were RT-PCR negative with a specificity of $100 \%$ (95\% CI: $85.75-100 \%)$ (Figure 3). This results in a Cohen's $\kappa$ of 0.31 for samples tested at baseline. 
In a subset of 21/30 (70\%) patients, ALK FISH positive nuclei were assessed, and the percentage of positive nuclei ranged between $19 \%$ and $98 \%$ (median $=58 \%$ ). Receiver operator characteristics (ROC) were used to assess the relationship between the ratio of $A L K$ rearrangement positive cells in FISH analysis and the positive outcome in the RT-PCR test (Figure S2). With an area under the curve (AUC) of 0.572 (95\% CI: 0.341-0.782), no association was observed between FISH tumor cell positivity and false

Table 2 Patient characteristics

\begin{tabular}{lc}
\hline Characteristic & Patients \\
\hline $\mathrm{N}$ & 66 \\
Age, median [range] & $6433-85]$ \\
Sex & 31 \\
Female & 35 \\
Male & \\
Diagnosis & 66 \\
Adenocarcinoma & \\
Stage & 9 \\
III & 57 \\
IV & \\
ALK rearrangements & 33 \\
IHC & 30 \\
FISH & \\
\hline
\end{tabular}

$A L K$, anaplastic lymphoma kinase; IHC, immunohistochemistry; $\mathrm{FISH}$, fluorescence in-situ hybridization. negative RT-PCR test results in this subset of patients. Likewise, the primary tumor size [which was measured in $15 / 30$ (50\%) patients] was not associated with RT-PCR result positivity (AUC $=0.619$; 95\% CI: 0.278-0.890) (Figure S3). Additionally, the ratio of positive tests was comparable between the group with brain metastasis [3/7 (43\%)] positive and the group without brain metastasis [6/16 (38\%), positive fisher-exact test $\mathrm{P}$ value $=1.00]$. Importantly, there was no significant difference in test performance between samples stored in EDTA tubes [7/23 (30\%) positive] and samples stored in BCT DNA tubes [3/7 (43\%); positive fisher exact test $P$ value: 0.657].

There were 12 ALK FISH/IHC positive patients who had been started on ALK TKI therapy. Of the $9 A L K$ positive patients who were currently on TKI therapy, only one $(11 \%)$ yielded a positive fusion call. Interestingly, all 8 RT-PCR negative patients demonstrated an objective response to TKI treatment while the positively tested patient presented with a stable disease according to RECIST v1.1 (not shown). The remaining three nonbaseline $A L K$ positive patients were tested by RT-PCR at progression under TKI treatment, and two patients $(66 \%)$ had a positive test result.

\section{Discussion}

The detection of $A L K$ rearrangements at baseline in advanced lung cancer patients is mandatory to allow for the initiation of a targeted treatment. While the detection from tissue samples is routinely implemented as a gold standard, liquid biopsies are not well established and are challenging in this setting (8). Importantly, recent reports

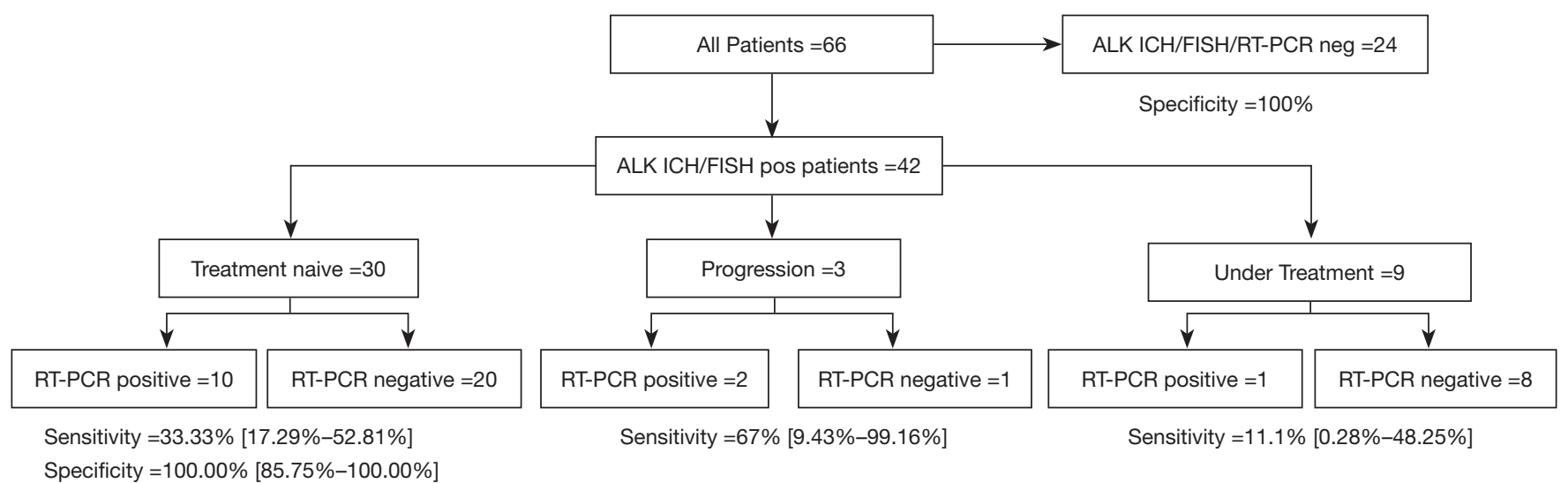

Figure 1 Flowchart and results of RT-PCR assay. The 95\% confidence interval is highlighted in brackets. RT-PCR, reverse transcription PCR. 
have demonstrated the use of NGS-based liquid biopsies; however, they did not compare the results directly to tissue sections or studied only a limited number of ALK-fusion positive patients $(9,10)$. Using the here reported RT-PCR

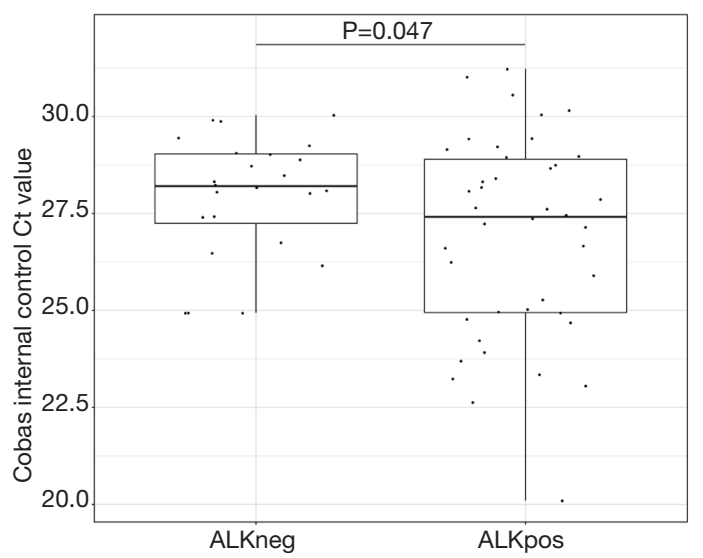

Figure 2 Boxplot comparing the positive control between the ALK positive and the ALK negative group. Ct values of the positive control in the assay are shown. Student's t-test two sided was used to compute the $\mathrm{P}$ value. ALK, anaplastic lymphoma kinase. assay, we were able to detect $A L K$ rearrangements from cfRNA with a sensitivity of $33 \%$ in baseline samples that were diagnosed based using FISH/IHC. ROC analyses of FISH nuclei positivity and primary tumor size did not show any association with ALK RT-PCR positivity of plasma specimens. However, we saw an inverse correlation between the total amount of extracted cfRNA and the internal control $\mathrm{Ct}$ value, which indicates that an increase of the plasma volume could increase the sensitivity of the assay. While the results are admittedly lower than expected, they are comparable to the results from recently reported NGS-based liquid biopsies assays made at baseline. Itotani et al. reported in a meeting abstract a positive percent agreement (PPA) of $44 \%$ for $A L K$ fusions tested in tissue and circulating free DNA (cfDNA) with the majority of fusions only detected in the tissue samples using the Guardant 360 (Redwood City, CA-USA) assay (11). This result was independently confirmed by Supplee $e t$ al. who demonstrated a sensitivity of $50 \%$ using the same NGS assay (12). It is important to note that these studies used an NGS assay for both tissue and plasma testing, whereas this present study used FISH and IHC for tissue testing and RT-PCR for plasma testing. Similarly, Mezquita

Description of ALK rearrangements

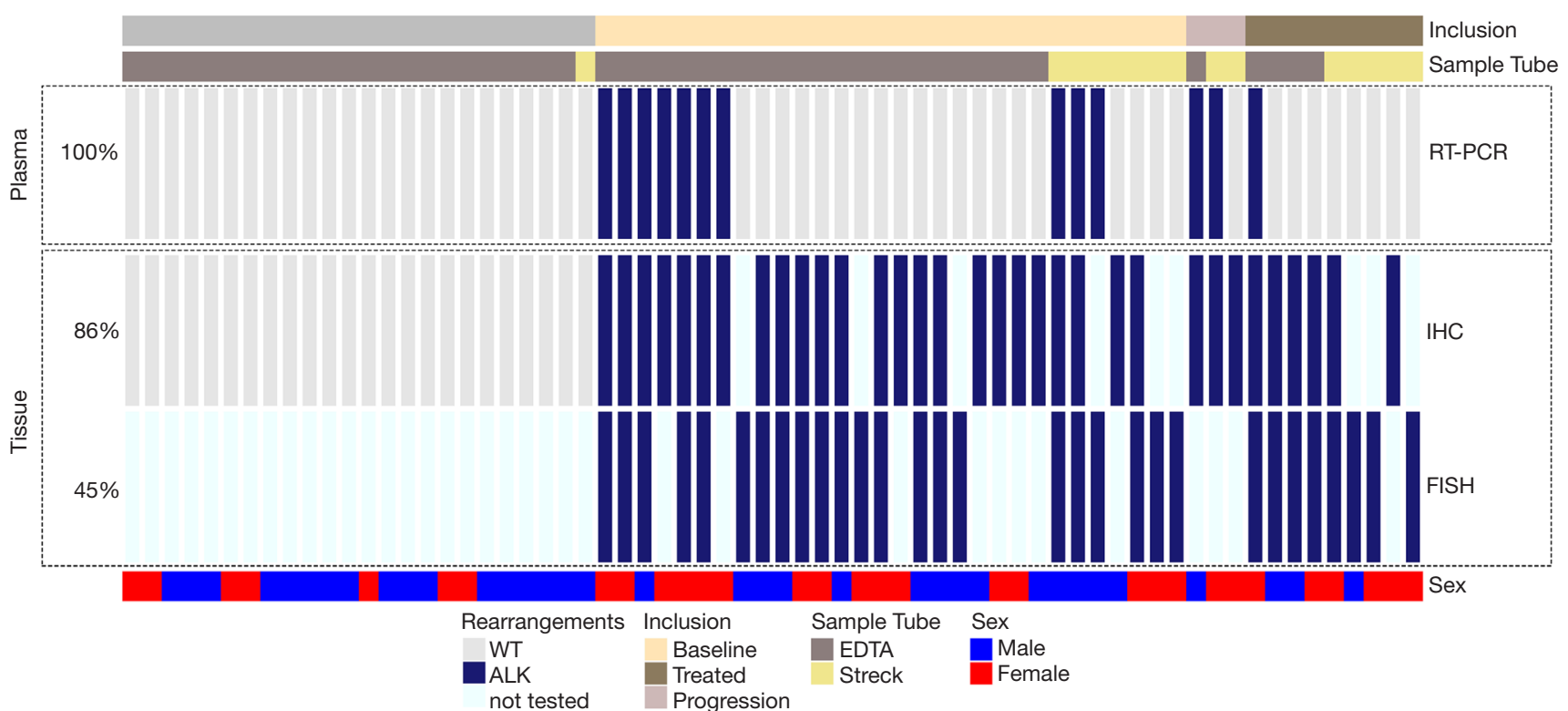

Figure 3 Oncoprint of $A L K$ rearrangements. The detection of $A L K$ rearrangements using the liquid biopsy RT-PCR assay (upper box) and the detection of ALK rearrangements from tissue (lower box) is highlighted. Additionally, the inclusion and blood collection tube are highlighted above, as well as the sex and age of the patients (below). The percentage of samples tested with the respective methods are highlighted to the left. ALK, anaplastic lymphoma kinase; RT-PCR, reverse transcription PCR. 
et al. reported a sensitivity of $67 \%$ at baseline, $46 \%$ at progression, and $11 \%$ under treatment, respectively for $A L K$ and ROS1 rearrangements using the InVisionFirstLung NGS assay (Inivata, Morrisville, NC-USA) for plasma testing and a combination of FISH, IHC, and NGS for tissue testing (13). Interestingly and in line with the results reported in this study, a higher detection rate was observed in patients at progression than those under active anti- $A L K$ treatment, suggesting that longitudinal tracking of $A L K$ rearrangements under treatment might be predictive of response to therapy. Noteworthy, while most of the NGS studies used outsourced tests requiring an increased amount of blood (up to $30 \mathrm{~mL}$ of whole blood), the here reported RT-PCR assay used only $2 \mathrm{~mL}$ of plasma. Additionally, the turn-around time for the outsourced NGS tests is usually 1-2 weeks, whereas test results for the RT-PCR results can be obtained in less than one day. However, the coverage of RT-PCR tests is limited to fewer rearrangements and requires prior knowledge of variants, such as the known fusions detected in the present assay. In contrast, NGS panels are able to identify a broader spectrum of genomic rearrangements and especially newer assays analyzing the $5 ' / 3$ ' imbalances have the potential to discover previously unreported fusion variants, which should increase the sensitivity (3). Also qRT-PCR based assays for the detection of novel variants using $5^{\prime} / 3^{\prime}$ imbalances have been developed for tissue samples and might also be adapted for its use in liquid biopsies (14). Indeed, one of the discordant plasma samples in this study, that was reported to be $A L K$ fusion negative by RT-PCR but $A L K$ fusion positive by IHC/FISH, was later sequenced on an NGS panel revealing a $K L C-A L K$ fusion that is not covered by the RT-PCR assay. Importantly, the RT-PCR assay is also capable of detecting ROS1 fusions by adding a second reaction, which would detect the most frequent druggable fusion variants in NSCLC in one single assay. However, the ROS1 assay was not assessed in the present study as only a cohort of $A L K$ positive patients was included and thus evaluation of the detection of RET or ROS1 rearrangements need to be performed independently.

Discordance between tissue and plasma-based tests have been attributed to biological factors such as tumor heterogeneity, tumor stage, and the variability in tumor shedding, which influences the amount of detectable mutant copies in liquid biopsies. Additionally, the here reported RT-PCR assay uses cfRNA rather than cfDNA. While there is still no consensus whether cfRNA is more suitable than cfDNA for ALK fusion detection from plasma, fusion
RNA has interestingly been reported in exosomes isolated from plasma as well as in blood platelets (15). Therefore, other important factors to consider are the pre-analytical methods used during the whole blood collection and plasma processing steps $(16,17)$. Importantly, the samples in this cohort were not specifically prepared for a cfRNA assay but used a protocol that was validated for the extraction of cfDNA. Consequently, adapting pre-analytical steps specifically for the use of cfRNA could also improve sensitivity of the assay. For example, the implementation of a double centrifugation spin during plasma separation, such as the one used in this study, may have adversely affected the recovery of exosomes and specifically other larger extracellular vesicles like macrovesicles or apoptotic bodies that might also contain significant amounts of RNA (data not shown). Additionally, due to the low stability of cfRNA, cooling of the blood directly after phlebotomy until plasma preparation might also be advised and was not performed in this protocol. Also, the use of blood collection tubes designed specifically to stabilize cfRNA may improve assay sensitivity. Further evaluation of pre-analytical methods is consequently urgently needed to determine the impact on assay performance and to establish standardized procedures for cfRNA processing.

\section{Conclusions}

Despite some limitations in sensitivity and spectrum of detected $A L K$ rearrangements, this new RT-PCR assay was still able to detect $A L K$ rearrangements in one third of patients, highlighting that a cfRNA-based RT-PCR assay using limited amounts of plasma is feasible. Admittedly, the low sensitivity highlights that a tissue biopsy remains standard of care. However, detecting $A L K$ fusions in cfRNA could not only spare some patients an invasive procedure but also allow for longitudinal evaluation of fusion status. Nevertheless, improving the sensitivity of such an assay should be of highest priority to allow widespread implementation in routine clinical care.

\section{Acknowledgments}

Part of this research has been presented at the AACR 2020: 10.1158/1538-7445.AM2020-5299.

Funding: Reagents were kindly provided by Roche Molecular Systems, Inc., Pleasanton, CA, USA. This work was supported by the French Government (National Research Agency, ANR) through the "Investments for 
the Future" programs LABEX SIGNALIFE ANR-11LABX-0028-01 and IDEX UCAJedi ANR-15-IDEX-01. This study was financially supported by a governmental grant from the French National Institute of Cancer (INCa PHRC; STALKLUNG01 13-APN-01), the "Cancéropôle PACA" and the "Conseil Départemental des AlpesMaritimes".

\section{Footnote}

Reporting Checklist: The authors have completed the STARD reporting checklist. Available at http://dx.doi.org/10.21037/ atm-20-7900

Data Sharing Statement: Available at http://dx.doi. org/10.21037/atm-20-7900

Peer Review File: Available at http://dx.doi.org/10.21037/ atm-20-7900

Conflicts of Interest: All authors have completed the ICMJE uniform disclosure form (available at http://dx.doi. org/10.21037/atm-20-7900). SH reports personal fees from Qiagen, personal fees from Boehringer Ingelheim, other from Roche, outside the submitted work. JM is member of the advisory board of Merck, Roche, Astra-Zeneca, MSD, BMS, Pfizer, Hengrui, Daiichi, Boehringer, Pierre Fabre and reports research grants from Roche, Astra-Zeneca, Pierre Fabre. JR, ML and EO are full time employees from Roche Molecular Diagnostics, and have a patent App. No. 62/513,226 pending. DMS reports personal fees from Roche, Pfizer, Takeda, Abbvie, BMS, MSD, Astra Zeneca, Becton Dickinson, Novartis, Boehringer Ingelheim, outside the submitted work. MGD reports personal fees from AstraZeneca, BMS, Boehringer Ingelheim, Roche Diagnostics and grants and personal fees from Takeda, outside the submitted work; PH reports personal fees from Roche, Astra Zeneca, BMS, Novartis, Merck, MSD, Qiagen, Thermo Fisher, Biocartis, outside the submitted work. $\mathrm{PH}$ serves an unpaid editorial board member of Annals of Translational Medicine from Jul 2020 to Jun 2022. The authors have no other conflicts of interest to declare.

Ethical Statement: The authors are accountable for all aspects of the work in ensuring that questions related to the accuracy or integrity of any part of the work are appropriately investigated and resolved. All patients provided signed informed consent and the study was approved by the local ethics committee (No: 2014-A0041740 ) and complied with the declaration of Helsinki (as revised in 2013).

Open Access Statement: This is an Open Access article distributed in accordance with the Creative Commons Attribution-NonCommercial-NoDerivs 4.0 International License (CC BY-NC-ND 4.0), which permits the noncommercial replication and distribution of the article with the strict proviso that no changes or edits are made and the original work is properly cited (including links to both the formal publication through the relevant DOI and the license). See: https://creativecommons.org/licenses/by-nc-nd/4.0/.

\section{References}

1. Skoulidis F, Heymach JV. Co-occurring genomic alterations in non-small-cell lung cancer biology and therapy. Nat Rev Cancer 2019;19:495-509.

2. Planchard D, Popat S, Kerr K, et al. Metastatic non-small cell lung cancer: ESMO Clinical Practice Guidelines for diagnosis, treatment and follow-up. Ann Oncol 2018;29:iv192-237.

3. Bruno R, Fontanini G. Next Generation Sequencing for Gene Fusion Analysis in Lung Cancer: A Literature Review. Diagnostics 2020;10:521.

4. Ilié M, Mazières J, Chamorey E, et al. Prospective multicenter validation of the detection of ALK rearrangements of circulating tumor cells for non-invasive longitudinal management of patients with advanced non-small cell lung cancer. J Thorac Oncol 2021;16:807-16.

5. Heeke S, Benzaquen J, Hofman V, et al. Critical Assessment in Routine Clinical Practice of Liquid Biopsy for EGFR Status Testing in Non-Small-Cell Lung Cancer: A Single-Laboratory Experience (LPCE, Nice, France). Clin Lung Cancer 2020;21:56-65.e8.

6. Ilie MI, Bence C, Hofman V, et al. Discrepancies between FISH and immunohistochemistry for assessment of the ALK status are associated with ALK 'borderline'-positive rearrangements or a high copy number: a potential major issue for anti-ALK therapeutic strategies. Ann Oncol 2015;26:238-44.

7. Begovich A, Dua R, Kuo D, et al. Multiplex PCR to detect gene fusions. USA; US10253349B2, 2016.

8. Hofman P, Paul. ALK Status Assessment with Liquid Biopsies of Lung Cancer Patients. Cancers (Basel) 2017;9:106.

9. Leighl NB, Page RD, Raymond VM, et al. Clinical Utility 
of Comprehensive Cell-free DNA Analysis to Identify Genomic Biomarkers in Patients with Newly Diagnosed Metastatic Non-small Cell Lung Cancer. Clin Cancer Res 2019;25:4691-700.

10. Gadgeel SM, Mok TSK, Peters S, et al. Phase II/III blood first assay screening trial (BFAST) in patients (pts) with treatment-naïve NSCLC: Initial results from the ALK+ cohort. Ann Oncol 2019;30:v918.

11. Itotani $\mathrm{R}$, Matsumoto $\mathrm{S}$, Udagawa $\mathrm{H}$, et al. A large scale prospective concordance study of oncogene driver detection between plasma- and tissue-based NGS analysis in advanced non-small cell lung cancer (NSCLC). Ann Oncol 2019;30:v602-60.

12. Supplee JG, Milan MSD, Lim LP, et al. Sensitivity of nextgeneration sequencing assays detecting oncogenic fusions in plasma cell-free DNA. Lung Cancer 2019;134:96-9.

13. Mezquita L, Swalduz A, Jovelet C, et al. Clinical Relevance of an Amplicon-Based Liquid Biopsy for Detecting ALK and ROS1 Fusion and Resistance Mutations in Patients

Cite this article as: Heeke S, Benzaquen J, Vallee A, Allegra M, Mazieres J, Fayada J, Rajamani J, Lee M, Ordinario E, Tiotiu A, Cadranel J, Poudenx M, Moro-Sibilot D, Barlesi F, Gervais R, Thariat J, Tanga V, Boutros J, Ilié M, Hofman V, Marquette $\mathrm{CH}$, Denis MG, Hofman P; on behalf of the STALKLUNG01 Study Consortium Investigators. Detection of ALK fusion transcripts in plasma of non-small cell lung cancer patients using a novel RT-PCR based assay. Ann Transl Med 2021;9(11):922. doi: 10.21037/atm-20-7900
With Non-Small-Cell Lung Cancer. JCO Precis Oncol 2020;(4):272.

14. Tong $\mathrm{Y}$, Zhao Z, Liu B, et al. 5'/ 3' imbalance strategy to detect ALK fusion genes in circulating tumor RNA from patients with non-small cell lung cancer. J Exp Clin Cancer Res 2018;37:68.

15. Park CK, Kim JE, Kim MS, et al. Feasibility of liquid biopsy using plasma and platelets for detection of anaplastic lymphoma kinase rearrangements in non-small cell lung cancer. J Cancer Res Clin Oncol 2019;145:2071-82.

16. Markus H, Contente-Cuomo T, Farooq M, et al. Evaluation of pre-analytical factors affecting plasma DNA analysis. Sci Rep 2018;8:7375.

17. Sherwood JL, Corcoran C, Brown H, et al. Optimised PreAnalytical Methods Improve KRAS Mutation Detection in Circulating Tumour DNA (ctDNA) from Patients with Non-Small Cell Lung Cancer (NSCLC). PLoS One 2016;11:e0150197. 


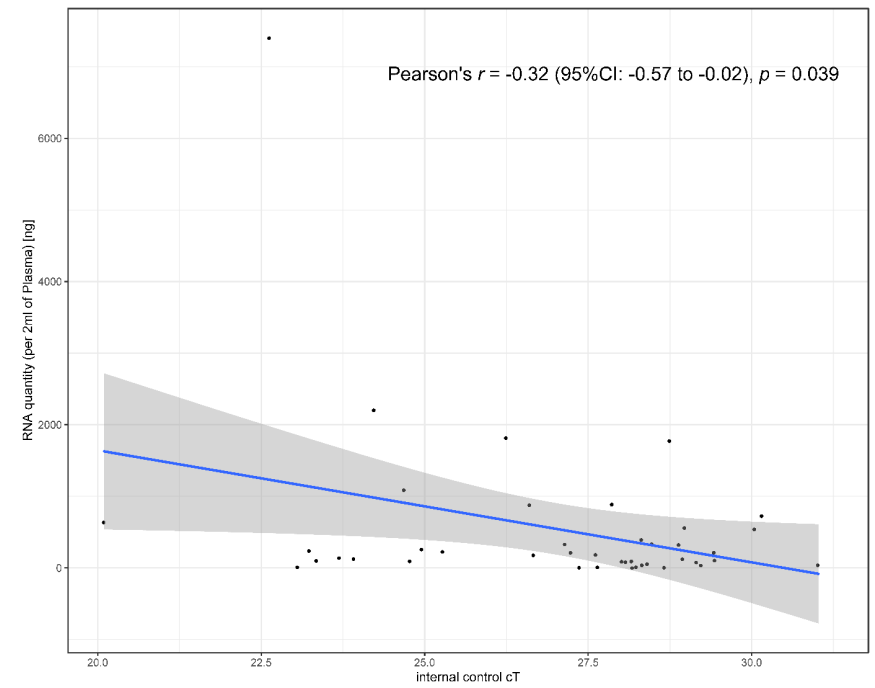

Figure S1 Correlation between total RNA input and the internal control Ct values obtained by qPCR. The blue line highlights the trendline with the $95 \%$ confidence interval presented in the shaded area. Pearson correlation has been used to calculate the correlation bet ween the values.

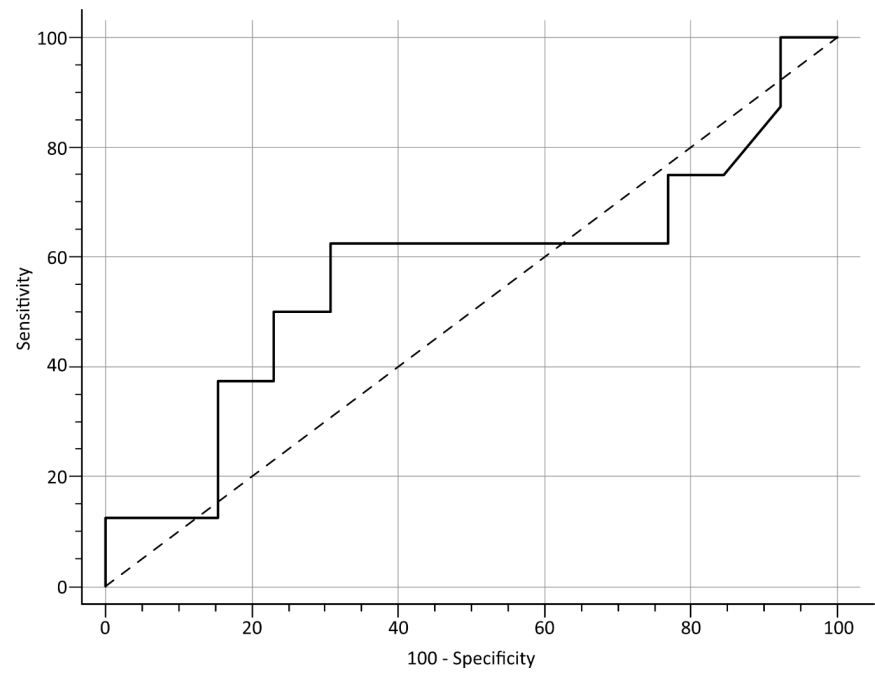

Figure S2 ROC curve for the association of the ratio of $A L K$ rearranged positive cells in the FISH analysis on tissue sections and positive outcome in the qPCR test in the baseline patients with known $A L K$ rearrangements. ROC, receiver operator characteristics; $A L K$, anaplastic lymphoma kinase; FISH, fluorescence in-situ hybridization. 


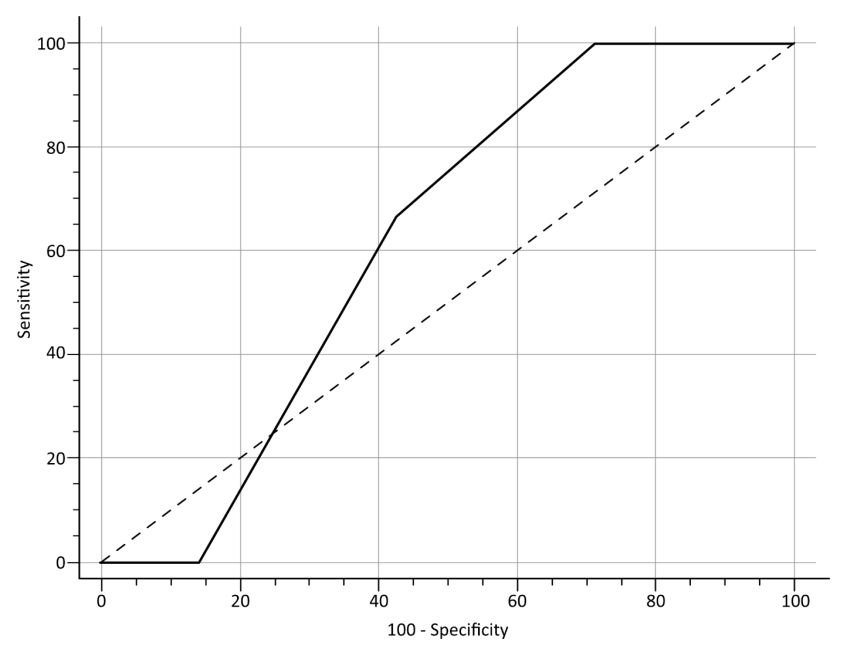

Figure S3 ROC curve for the association of the primary tumor size and positive outcome in the qPCR test in the baseline patients with known $A L K$ rearrangements. ROC, receiver operator characteristics; $A L K$, anaplastic lymphoma kinase. 